\title{
Disposition of Pathogenic Flora in the Development of Nonspecific Ulcerative Colitis
}

\author{
Shaposhnikov Veniamin Ivanovich* \\ Professor of surgical diseases, Vice Rector, Russia \\ *Corresponding author: Shaposhnikov Veniamin Ivanovich, Professor of surgical diseases, Vice Rector, Russia
}

\begin{tabular}{|c|c|}
\hline ARTICLE INFO & ABSTRACT \\
\hline Received: 豐 April 03, 2019 & The author watched 38 patients with nonspecific Ulcerative Colitis (UC) had expressed these \\
\hline Published: April 08, 2019 & $\begin{array}{l}\text { dis-ease manifestations of an enteric. Development of a pathological process, he associates with the } \\
\text { dislocation of pathogenic microflora of the channel anus rectum in the lumen of the colon that occurred }\end{array}$ \\
\hline
\end{tabular}

Ivanovich. Disposition of Pathogenic Flora in the Development of Nonspecific Ulcerative Colitis. Biomed J Sci \& Tech Res 16(5)-2019. BJSTR. MS.ID.002919.

Keywords: Ulcerative Colitis; Enema; Dislocation; Pathogenic Flora

\section{Introduction}

Ulcerative colitis refers to the number of diffuse chronic recidivating diseases of the colon, which mainly affected its mucous membrane [1-5]. UC meets throughout the world. In year 3 to 15 of diagnosed new observations on 100000 of the population, and the incidence of reaches 50-80. Men and women have equally often. The first peak of the detect ability of age from 20 years old do 40 , the second 60-70 years (2.7). At present, there is no clear information about the etiology and pathogenesis of this disease. It is expected that the development of wheatgrass is the breakdown of immunological tolerance to intestinal antigens. The result is a loss of immunological control of inflammation in the wall of the small and large intestines (2.6). It is believed that this pathological process normally resists low doses of endogenous Gljukokortikosteroidov (GKS), which in a cage are associated with the specific gljukokortikosteroidnymi zitoplazmaticakimi receptors.

This complex enters the nucleus of the cell and is in contact with DNK elements in the region are glukokortikoida specific genes. The result is a suppression gene encoding the transcription of inflammatory proteins, especially signaling molecules cascade MAPK (mitogen-activated protein kinas). Parallel synthesis inhibitor-IkBa amplifies a key transcription factor NFkB, allowing specific RNK transport education is sup-pressed (m-RNK) and shortened the period of their half-life. Since $\mathrm{m}$-RNK is responsible for regula-tion of synthesis and release of inflammatory cytokines TNF-a, IFN-y, IL-23, IL-17of others in-volved in the inflammatory response, in appointing GCS level their decline [6-8]. This also reduces education arachidonic acid and its subsequent metabolism with the formation of leukotrienes and prostaglandins [9]. When UC holds a mixture of inflammatory reaction involving the t-helper cells as the $1^{\text {st }}$ and $2^{\text {nd }}$ types (6.8). The most often considered to be a hereditary predisposition to the development of autoimmune inflammation in the mucosa of the colon in response to sowing surface microorganisms and viruses, as well as contact the impact food. This opinion is based on the frequent combination of UC with other autoimmune processes (3.8). The discovery of same in colon mucosa of IgG-antibody to epithelial cells and p-ANCA only strengthened the position of the supporters of this hypothesis. Completed studies to determine the ratio of t-lymphocytes in the mucosa of the colon indicate violation agent's interactions activated CD4 and CD8 lymphocytes. Normal epithelial cells stimulate the predominantly CD8-T cells. While at UC they activate CD4 lymphocytes exclusively and is accompanied by IL-2 secretion of lymphocytes and stimulation of macrophages in the complement system. Identified and family history of UC, with first-line relatives fall sick more often than the average population, as well as the risk factors they have clearly seen the use of oral contraceptives, as well as features nutrition and psychosocial problems (3.5). Literature 
data suggest an important role of normal intestinal microflora in the adaptation reaction of human organism to the age changing his life (3.8). In view of these data, the reason becomes clear when you change syn-drome pathological development of microflora of the colon. At a young age caused for one reason or another, intestinal symbiosis is accompanied by diarrhea, coupled with the brodilnym process. Every fifth patient in this age group are marked with allergic dermatitis, occurring against the backdrop of autonomic expressed violations.

Dysbacteriosis of the same link with a postponed intestinal infection and long treatment with antibiotics. Performed bacteriological researches in this group of patients indicate expressed growth suppression of Escherichia coli with a simultaneous settlement of the lu-men of the colon of conditionally pathogenic microflora (enterobacteria, citrobakterii, Klebsiella, Pro-teus, fungi kind Candida, gemolizirujushhie strains of Escherichia, etc.). Individuals have the same maturity (40-59 years), in which there is persistent constipation alternating with diarrhea, bacterial painting Calla proportion of functionally defective (lactosenegative and enzymatically attenuated) strains of e. coli, which occurs against the backdrop of moderate decline bifidumbakterij growth. The same persons over the age of 60 years, suffering persistent constipation, the feces noted a sharp de-cline in the obligate microflora (Lactobacillus bifidum and Lactobacillus) while increasing the level of conditionally pathogenic microflora [2]. Infections often cause the development and exacerbation of wheatgrass, because one way or another damaged mucosa easily kontaminiruetsja pathogenic microflora (3.8). UC have detected symptoms of a enteric $20 \%$ of patients. They include Nodular Erythema, gangrenoznaya Pyoderma, inflammatory eye diseases, arthritis, ankylosing spondylitis, respiratory dysfunction, Myositis, Vasculitis, Glomerulonephritis, and other pathological processes outside the walls of the colon guts (3.5). If the role is conditionally pathogenic microflora in the development of the UC clearly understood, here's its settlement mechanism of the colon remains unclear. The definition of these ways and was the purpose of this study.

\section{Material and Methods}

Watched 38 patients with UC had expressed enteric (kostnoarticulate) symptoms manifesta-tions of the disease, which has resulted in their hospitalization in the casualty department. Only in the course of the survey, they had identified the true cause of the painful condition, i.e. the UC. All of these patients, whose age was from 42 to 68 years, suffered from distorting the artrozami joints of the lower limbs and ankylosing spondylitis. Men was 16 (42.2\%). Upon admission to the hospital all patients stressed doctors' osteoarticular pathologies and umalchivali about the problems associated with the Act of defecation. Only through the 2-3 days after hospitalization, they began to bring complaints of liquid stool mixed with blood and mucus in the stool. Frequency defekacij reaches 5-6 times per day. In patients suspected of having perpetuated was food toksikonfekcija and diagnostic measures have been made. When you run rectoromanoscopy, attention was drawn to the existence of patients with redness, maceration, and cracks in the perianal region. Endoscopic study found the typical symptoms of chronic (or relapsing, or continuously-relapsing) wheatgrass. Bacteriological study of tissue taken from the surface of the detritus Armenian revealed microbial Association of Klebsiella, Proteus, gemolizirujushhih esherihi and etc. After verification of diagnosis was assembled a de-tailed life in this direction. It was found that all patients with adolescence suffered from constipation.

The Chair was only a day, and sometimes through the 2-3 days. With age the constipation has become persistent nature and without enemas achieved defecation them failed. Patients often resorted to staging of salt, soap, oil and other enemas, which appeared in the left iliac region pain and tenesmus after defecation. In the last year before the hospitalization in the stake appeared mucus and blood veins. For medical assistance. These changes in the Act of urinating associated with frequent taking enemas. Osteoarticular diseases they have began to develop after 30 years. After ascertaining the true causes of painful condition, patients were placed in a specialized unit. During the specific treatment, with the use of corticosteroids, 2 of them (5.2\%) microperforation occurred altered sigmoid colon walls. They were transferred to the Department of surgery with primary acute peritonitis phenomena. Both patients was the primary submersible kolokoloanastomoz.

\section{Result}

These 2 patients of postoperative complications were observed. After the stitches have been medication they have continued in the therapeutic Department. The remaining 36 patients of such surgical complications were observed. Treatment took place in the therapeutic Department and had a positive effect is difficult. Continued to harass pain in the joints and spine.

\section{Discussion}

Development of a pathological process in these patients can be associated with a dislocation of the virulent Microbe flora of anus the Canal in the lumen of the colon that occurred during staging enemas. Resort to this method of release of the rectum from the faeces of patients forced to constant constipation, and they had them with adolescence. The aggravation of the same they have UC on the 2-3 day after the hospital casualty department could explain the sharp changes the nature of power and of psycho-emotional loads. Duration of intensive integrated inpatient treatment ranged from 18 to 22 days, and then was an outpatient. Spring and autumn came.

\section{Conclusion}

Thus, as a factor that contributes to the development of UC may include deployment of microbial flora of the channel anus in the lumen of the colon that occurs when setting enemas. Clearly an allergic and autoimmune nature of its origin. Disease is 
tenacious in nature and it is difficult to treat and, for this reason, the focus should be paid to prevention. Behind the seeming enema bezobidnostju hide terrible consequences. For this reason the issue of defecation everyone should pay close attention to and follow its daily accomplishment, through a balanced diet and active lifestyle.

\section{References}

1. Vorobev GI, MikhailovaTl, Kostenko NV (2006) Attainable satisfactory results of surgical treatment of ulcerative colitis? Coloproctology 2(16): 34-42.

2. Golovenko OV, Mikhailova Tl, Ilyuschenko VS (2006) Clinical features of ulcerative colitis in patients older. Coloproctology 2(16): 21-24.

3. Zhelnova TI (2003) Kandidozny dysbacteriosis of the intestine: Clinical features. Current issues of Coloproctology, pp. S423-S424.

\section{ISSN: 2574-1241}

DOI: 10.26717/BJSTR.2019.16.002919

Shaposhnikov Veniamin Ivanovich. Biomed J Sci \& Tech Res

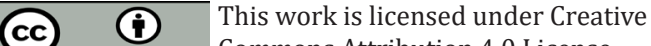

Submission Link: https://biomedres.us/submit-manuscript.php
4. Ivashkina V, Komarova FI, Rapoport SI (2001) Quick start guide for gastroenterology. House of m-Lead, pp. 458.

5. Golovenko OV, Kapuller LI, Mikhailova TI, Veselov VV, Caliph II (2005) Nonspecific colitis in the spectrum of inflammatory bowel disease. Coloproctology 4(14): 33-34.

6. Sekachev MI (2003) Modern aspects of treatment of nonspecific ulcerative colitis; the results of evidence-based medicine. Consilium medicum 3: 18-22.

7. Caliph II (2006) Principles of treatment of ulcerative colitis. Coloproctology 3(17): 31-34.

8. Yakovleva OG, Zhelnova TI, Hivinceva OA (2003) Mikrobiotenoz bowel syndrome in different age groups: Clinical features. Actual questions of Coloproctology, pp. 439-441.

9. Stack WA, Long RG, Hawkwy CJ (1998) Short-and long-term outcome of patients treated with cyclosporine for severe acute ulcerative colitis. Aliment Pharmaco-logic There 12: 973-978.

$\begin{array}{ll}\text { BIOMEDICAL } & \text { Assets of Publishing with us } \\ \text { RESEARCHES } & \text { - Global archiving of articles } \\ & \text { - Immediate, unrestricted online access } \\ & \text { - Rigorous Peer Review Process } \\ & \text { - Authors Retain Copyrights }\end{array}$

